\title{
USEFULNESS OF TRANSCUTANEOUS ULTRASOUNOGRAPY VERSUS COMPUTED TOMOGRAPHY IN THE ASSESSMENT OF CANCER LARYNX
}

\author{
Hossam Abdel Kader Morsy*, Reem Hassan Ibrahim Bassiouny*, Fady Mamdouh \\ FawzyTadros*, Amina Mohamed Ahmed
}

* Department of Radiology, Faculty of medicine, Ain Shams University, Cairo, Egypt.

.Corresponding author:

Amina Mohamed Ahmed Farag

Mobile: 01227890348

E mail:

firstmanos@hotmail.com.

Received: 12/5/2019

Accepted: 9/6/2019

\section{ABSTRACT:}

Background: The use of ultrasonography as a complementary diagnostic tool to CT in the assessment of cancer larynx has always been underestimated due to the anatomical obstacles in the form of thyroid cartilage calcification yet specific anatomic sites with proper technique implementation raised the sensitivity and specificity of the sonographic results and presented it as a trustable screening tool taking advantage of its additional dynamic criteria.

Aim of work: To evaluate the usefulness of ultrasonography versus Computed Tomography in assessing cancer larynx.

Patients and Methods: 46 patients with histopathologically proven laryngeal carcinoma were enrolled after exclusion of 5 patients from surgery. A comparative assessment was made between the detection rate of localization and sensitivity, specificity, $P P V, N P V$ and accuracy of pre-therapeutic ultrasonography compared to CT with post operative pathology as a standard reference.

Results: Most of the patents were males [47(92.2\%)/51] and aged $>60$ years [25(49\%)/51]. The detection rate was highest in glottic lesions being the same in both ultrasonography and CT [32 (96.9\%)/33] with a sensitivity and specificity of $90.9 \%$ and $84.6 \%$ versus $93.9 \%$ and $92.3 \%$ in each modality respectively. $(p=0.000)$. The specificity, sensitivity, PPV, NPV and accuracy results of invasion of the intra-laryngeal structures were comparable for both modalities: U/S and CT in detection of thyroid cartilage invasion being $88.8 \%$, $89.3 \%$, $84.2 \%, 92.5 \%$ and $89.1 \%$ for U/S versus $88.8 \%, 96.4 \%$, 94.1\%, 93.1 and $93.4 \%$ for CT, paraglottic fat infiltration being 90.3\%, 86.7\%, 93.3\%, 81.2\% and $89.1 \%$ for U/S versus $93.5 \%$, 93.3\%, 96.7\%, 87.5\% and 94.4\% for CT and anterior commissure infiltration being $88.5 \%, 90 \%, 92 \%, 85.7 \%$ and $89.1 \%$ for U/S versus $96.2 \%, 100 \%, 100 \%, 95.2 \%$ and $97.8 \%$ for CT.

Conclusion: Ultrasonography could be used as a valuable supplementary imaging method to CT and laryngoscopy in the assessment of laryngeal carcinoma, even in male adults with some calcifications of the thyroid cartilage.

Keywords: Cancer larynx, Glottic lesions, paraglottic fat infiltration, anterior commissure infiltration, thyroid cartilage infiltration, transglottic infiltration.

\section{INTRODUCTION:}

Laryngeal cancer accounts for approximately one quarter of the head and neck malignancies worldwide, and the overall survival, disease free survival and laryngeal reservation are largely determined 
by the initial tumor stage at the time of the diagnosis ${ }^{1}$.

A vast majority of these cancers are squamous cell carcinoma (SCC). Tobacco smoking and alcohol consumption are important risk factors for laryngeal SCC, those patients have a higher risk for synchronous malignancies arising from the lung and aerodigestive tract ${ }^{2}$.

Early identification of malignant laryngeal neoplasms results in improved prognosis and functional outcomes. Imaging plays an integral role in the diagnosis, staging and long term follow up of cancer larynx ${ }^{3}$.

Cross sectional imaging with contrast enhanced CT allows excellent depiction of the detailed anatomy of the larynx and the characteristic pattern of submucosal tumor extension. It also provides vital information about the status of cervical nodal disease, systemic metastasis and any synchronous malignancies as well as post therapeutic tumor recurrence in these patients. Additionally, certain image based parameters like tumor volume and cartilaginous abnormalities have been used to predict the success of primary radiotherapy or surgery in these patients ${ }^{2}$.

High frequency ultrasonography is routinely used as an imaging method to evaluate the involvement of cervical lymph nodes, soft tissues and thyroid gland in patients with laryngeal carcinoma, but rarely to evaluate the tumor itself and its invasion of the intralaryngeal structures, mainly because of the calcified thyroid cartilage in adults and the interference of air within the laryngeal cavity. Nevertheless, attempts have been made to use ultrasonography in this area to take advantage of its non invasive and real time imaging features ${ }^{1}$.

Our study aims at demonstrating that ultrasonography, which has been used scarcely in the larynx, could supply useful information the detection, localisation, intra and extralaryngeal invasion of laryngeal carcinoma ${ }^{3}$.

Generally tumours are hypoechoic sonographically and can easily be differentiated from the surrounding tissue especially in the hyperechoic supraglottic structures. Thyroid cartilage infiltration can be easily detected by the interruption of the hyperechoic inner perichondrium ${ }^{4}$.

Assessment of the para glottic space involvement and vocal cord fixation can be fairly detected by ultrasonography ${ }^{3}$.

Whether ultrasonography has similar ability to evaluate laryngeal carcinoma is worth studying as a supplementary imaging method to laryngoscope or $\mathrm{CT}^{\mathbf{1}}$.

\section{AIM OF THE WORK:}

To evaluate the usefulness of ultrasonography versus Computed Tomo-graphy in assessing cancer larynx.

\section{PATIENTS AND METHODS:}

A comparative study of two diagnostic tests: CT and ultrasonography, was done by clinical trial selecting 51 patients with pathologically proven cancer larynx from Ain Shams University Hospitals 47 are males and 4 females aged between 30 and 67 years along a period of about 2 years for data collection starting in August 2017 using convenient sampling method.

The pre-therapeutic U/S and CT were retrospectively evaluated including the tumor detection, localization and invasion of intra and extralaryngeal structures. All cases underwent direct laryngoscope and biopsy taking about 10 days prior to ultrasonographic assessment and CT of the neck was performed at the time period between laryngoscope and ultrasonography.

Laryngectomy was performed eventually to 46 patients and histopathological results were documented. 
The study population was selected according to the selected criteria as follow:

\section{Inclusion Criteria:}

- Patients histopathologically proven, newly diagnosed cancer larynx by direct laryngoscopy (10 days after the performance of the direct laryngoscopy), non operated and didn't receive any type of treatment except methods of securing the airway if needed as tracheostomy tube.

- $\quad$ No age predilection.

- Both sexes are included.

\section{Exclusion criteria:}

- Patients diagnosed to have cancer larynx and received any type of medical or surgical treatment whether curative or palliative

- Patients with contraindication for CT exposure, e.g. Pregnant females.

- Patients with contraindications to intravenous contrast administration, e.g. Patients allergic to the intravenous contrast administration, patients with toxic goiter, patients planned for radioiodine treatment of thyroid cancer.

- Patients refusing the intravenous contrast administration.

- Patients with respiratory of hemodynamic instability and inconvenience for the scan.

\section{Patient's preparations:}

\section{Patients were subjected to:}

1. Full history taking including drug history of allergic reaction to IV contrast.

2. Detailed explanation of the imaging procedure.

3. Consent taking for undergoing the study including contrast administration.

4. Recent serum creatinine level (within one week duration).
5. 4-6 hours fasting state.

6. Administration of 1 ante-cubital intravenous catheter

7. CT scan with IV contrast of the neck.

8. Transcutaneous ultrasonography of the larynx whether in the same setting or during a different hospital visit about 10 days after the laryngoscopic biopsy taking.

9. No interventional procedures were done.

\section{Study tools used along the research course were high-lightened as follow:}

The ultrasound machines (Linear probe $7 \mathrm{MHz}$, Samsung ACCUVIX XG 275-KB003A).

Acoustic windows that were suitable for the penetration of ultrasound beams were located at the thyrohyoid membrane, cricothyroid membrane and thyroid cartilage lamina, where the structure had less calcification. During scanning, the patient was instructed to hold and relax their breath or talk softly to evaluate the mobility of vocal cords and arytenoid cartilages. These maneuvers were also used to observe the relative movement of the paraglottic fat to the adjacent internal perichondrium of the thyroid cartilage.

Each study took about 3-4 minutes for laryngeal U/S.

The CT study was performed on CT machine (GE Bright Speed, 1023 CT 04), an 8 slices machine $\mathrm{x} 5 \mathrm{~mm}$ detector collimator with a field of view of $16 \mathrm{~cm}$ and slice thickness of $5 \mathrm{~mm}$ using $120 \mathrm{kV}, 220 \mathrm{mAs}$, 1.5 seconds rotation time, $1 \mathrm{~mm}$ interspace were obtained parallel to the plane of the true vocal cords from the skull base to the sternum and examination time of about 1 minute for $\mathrm{CT}$ of the neck with IV contrast injection bolus injection of $60-85 \mathrm{ml}$ of ultravist $\left(300 \mathrm{mgI} \mathrm{ml}^{-1}\right)$ by injector or by manual injection at a flow rate of $3 \mathrm{ml}$ 
$\mathrm{s}^{-1}$ with a 50 seconds delay, a dose of 1-2 $\mathrm{ml} / 10 \mathrm{~kg}$ patient body weight with maximum dose $100 \mathrm{ml}$. During scanning, patients were instructed to breathe quietly and to avoid swallowing or moving.

Images were reconstructed to axial, coronal and sagittal sections, with both the slice thickness and interspace being $5 \mathrm{~mm}$.

The patient is positioned supine on both $\mathrm{CT}$ and U/S with the neck extended slightly, each patient was scanned from the hyoid bone down to the inferior border of the cricoid cartilage in transverse, longitudinal and oblique planes.

The staging of laryngeal cancer was evaluated according to the guidelines of the American Joint Committee of Cancer (AJCC).

\section{Imaging analysis:}

\section{Radiographic points assessed by $U / S$ and}

\section{CT:}

1. Infiltration of the paraglottic space.

2. Subglottic infiltration.

3. Pre-glottic infiltration (anterior commissure).

4. Invasion of laryngeal cartilage.

5. Extra-laryngeal infiltration (tracheal rings and esophagus).

6. Ipsilateral lymph node affection (and size)

7. Contralateral lymph node affection (and size).

Additional radiographic points assessed by U/S only included:

1. Vocal cord mobility with phonation.
2. Vascularity (on Doppler imaging).

Thyroid cartilage, pre-epiglottic space, paraglottic space, thyroid and cervical soft tissues, lying in the larynx anteriorly or superficially, are easy to be imaged with a high-frequency probe. Commonly, these structures are isoechoic or hyperechoic, which provide a contrast with a hypoechoic invading tumour(Loveday et al, 1994) ${ }^{5}$.

Moreover, the paraglottic space normally manifests as a thin layer of fatty tissue that has some mobility during respiration in contrast to the immobility of adjacent inner perichondrium of thyroid cartilage (Chevallieret al,2002 ${ }^{6}$.

When the relative movement decreased or ceased or the fat is obliterated, it was helpful to diagnose the neoplastic spread to the paraglottic space.

We evaluated the mobility of the larynx by having the patients talk softly or relax after breath-holding. Asymmetrical movement or impaired mobility of the vocal cords and on real-time ultrasonography images was almost always associated with thyroid cartilage invasion with or without recurrent laryngeal nerve invasion upgrading the tumor to stage T4 (Loveday et al, 1994) ${ }^{5}$.

\section{reference standard:}

- The results of histopathological examination of the excised laryngeal tissue and draining lymph nodes were compared to the results obtained by CT and U/S examination performed prior to surgery and were used as a reference standard. 


\section{RESULTS:}

Most of the randomly sampled patients were males representing $92.2 \%(47 / 51)$ compared to $7.8 \%(4 / 51)$ female patients.

\begin{tabular}{|l|l|c|c|}
\hline \multicolumn{2}{|c|}{} & No. & $\%$ \\
\hline \multirow{4}{*}{ Age } & $30-40$ years & 2 & $3.9 \%$ \\
\cline { 2 - 4 } & $40-50$ years & 7 & $13.7 \%$ \\
\cline { 2 - 4 } & $50-60$ years & 17 & $33.3 \%$ \\
\cline { 2 - 4 } & $>60$ years & 25 & $49.0 \%$ \\
\hline \multirow{2}{*}{ Gender } & Females & 4 & $7.8 \%$ \\
\cline { 2 - 4 } & Males & 47 & $92.2 \%$ \\
\hline
\end{tabular}

The patients had mostly multiple presenting symptoms yet the main complaint was hoarsness of voice seen in $84.3 \%$ $(43 / 51)$, less frequent complaints either solely or combined were persistent dry cough in $45 \%(23 / 51)$, dyspnea in $19.6 \%$
(10/51), otalgia in $13.7 \%(7 / 51)$, dysphagia in $11.7 \%(6 / 51)$, life threatening stridor necessitating urgent tracheostomy insertion and ICU admission in $9.8 \%(5 / 51)$, weight loss in $7.8 \%(4 / 51)$, halitosis $5.9 \%(3 / 51)$ and hemoptysis in $3.9 \%(2 / 51)$.

\begin{tabular}{|l|l|c|c|}
\hline Presenting complaint & No. & $\%$ \\
\hline \multirow{2}{*}{ Hoarseness of voice } & No & 8 & $15.7 \%$ \\
\cline { 2 - 4 } & Yes & 43 & $84.3 \%$ \\
\hline \multirow{2}{*}{ Dysphagia } & No & 45 & $88.2 \%$ \\
\cline { 2 - 4 } & Yes & 6 & $11.8 \%$ \\
\hline \multirow{2}{*}{ Dyspnea } & No & 47 & $92.2 \%$ \\
\cline { 2 - 4 } & Yes & 4 & $7.8 \%$ \\
\hline \multirow{3}{*}{ Otalgia } & No & 41 & $80.4 \%$ \\
\cline { 2 - 4 } & Yes & 10 & $19.6 \%$ \\
\hline \multirow{3}{*}{ Halitosis } & No & 45 & $88.2 \%$ \\
\cline { 2 - 4 } & Yes & 6 & $11.8 \%$ \\
\hline \multirow{3}{*}{ Stridor } & No & 48 & $94.1 \%$ \\
\cline { 2 - 4 } & Yes & 3 & $5.9 \%$ \\
\hline Persistent dry cough & No & 46 & $90.2 \%$ \\
\cline { 2 - 4 } & Yes & 5 & $9.8 \%$ \\
\hline \multirow{2}{*}{ Hemoptysis } & No & 28 & $54.9 \%$ \\
\cline { 2 - 4 } & Yes & 23 & $45.1 \%$ \\
\hline \multirow{2}{*}{} & No & 49 & $96.1 \%$ \\
\cline { 2 - 4 } & Yes & 2 & $3.9 \%$ \\
\hline
\end{tabular}

On clinical examination, signs of locally advanced condition whether single or combined were detected in $23.5 \%(12 / 51)$ patients mainly in the form of cervical palpable lesions in $23.5 \%(12 / 51)$, diminished breath sounds due to airway compromise and/or precipitated pneumonia in $21.5 \%(11 / 51)$ and loss of laryngeal crepitus in $15.6 \%(8 / 51)$.

\begin{tabular}{|l|l|l|l|}
\hline \multicolumn{2}{|l|}{ Signs of advanced condition } & No. & $\%$ \\
\hline \multirow{2}{*}{ Loss of laryngeal crepitus } & No & 43 & $84.3 \%$ \\
\cline { 2 - 4 } & Yes & 8 & $15.7 \%$ \\
\hline \multirow{2}{*}{ Diminished breath sound } & No & 40 & $78.4 \%$ \\
\cline { 2 - 4 } & Yes & 11 & $21.6 \%$ \\
\hline \multirow{2}{*}{ Parotid, thyroid and cervical palpable lesions } & No & 39 & $76.5 \%$ \\
\cline { 2 - 4 } & Yes & 12 & $23.5 \%$ \\
\hline
\end{tabular}


Multiple risk factors were identified such as heavy smoking (20 cigarettes/day or more) in $94.1 \%(48 / 51)$, water pipe in 78.4 $\%(40 / 51)$ and hashish in $41.2 \%(21 / 51)$ yet combined cigarettes with water pipe in 72.5 $\%(37 / 51)$ and cigarettes with hashish in $35.3 \%(18 / 51)$ of the patients.

Prolonged smoke inhalation either residential or occupational was seen separate in $68.6 \%(35 / 51)$ and $35.3 \%(18 / 51)$ patients respectively and combined in 15.7 $\%(8 / 51)$ patients.

Alcohol consumption ( $>8$ units (45 $\mathrm{ml}) /$ week) was seen in $15.7 \%(8 / 51)$ patients all combined with only cigarettes or cigarettes with water pipe and/or hashish smoking.

GERD is seen in most of the patients $78.4 \%(40 / 51)$ being presented as sequel of the other risk factors as smoking rather than weak additional risk factor to worrisome chronic laryngeal irritation.

Unbalanced diet in the form of deficient fibrous diet (vegetables and fruits) was seen in $70.6 \%(36 / 51)$ regarded as a common.

Most of the patients were presented with immune compromised state due to one or combined pathological conditions such as $\mathrm{HCV}$ infection which was detected in $47 \%$ $(24 / 51)$ while $13.7 \%$ (7/51) were on regular steroid inhaler for associated asthma and $86.3 \%(44 / 51)$ had other co-morbidities such as diabetes and/or cardiac condition one of which necessitating regular treatment for more than 5 years.

Positive family history of malignancies was revealed in $29.4 \%(15 / 51)$

\begin{tabular}{|c|c|c|c|}
\hline \multicolumn{2}{|l|}{ Risk factors } & No. & $\%$ \\
\hline \multirow[t]{2}{*}{ Cigarettes $(>20 /$ day for $>1$ year) } & No & 3 & $5.9 \%$ \\
\hline & Yes & 48 & $94.1 \%$ \\
\hline \multirow[t]{2}{*}{ Water pipe } & No & 11 & $21.6 \%$ \\
\hline & Yes & 40 & $78.4 \%$ \\
\hline \multirow[t]{2}{*}{ Hashish } & No & 30 & $58.8 \%$ \\
\hline & Yes & 21 & $41.2 \%$ \\
\hline \multirow[t]{2}{*}{ Alcohol intake } & No & 43 & $84.3 \%$ \\
\hline & Yes & 8 & $15.7 \%$ \\
\hline \multirow[t]{2}{*}{ Balanced diet } & No & 36 & $70.6 \%$ \\
\hline & Yes & 15 & $29.4 \%$ \\
\hline \multirow[t]{2}{*}{$\mathrm{HCV}+\mathrm{ve}$} & No & 27 & $52.9 \%$ \\
\hline & Yes & 24 & $47.1 \%$ \\
\hline \multirow[t]{2}{*}{ Steroid ttt } & No & 44 & $86.3 \%$ \\
\hline & Yes & 7 & $13.7 \%$ \\
\hline \multirow[t]{2}{*}{ Other immune compromising co-morbidities } & No & 7 & $13.7 \%$ \\
\hline & Yes & 44 & $86.3 \%$ \\
\hline \multirow[t]{2}{*}{ Occupational exposure } & No & 34 & $66.7 \%$ \\
\hline & Yes & 17 & $33.3 \%$ \\
\hline \multirow[t]{2}{*}{ Residential exposure } & No & 16 & $31.4 \%$ \\
\hline & Yes & 35 & $68.6 \%$ \\
\hline \multirow[t]{2}{*}{ GERD } & No & 11 & $21.6 \%$ \\
\hline & Yes & 40 & $78.4 \%$ \\
\hline \multirow[t]{2}{*}{ Family history of Head and Neck malignancy } & No & 48 & $94.1 \%$ \\
\hline & Yes & 3 & $5.9 \%$ \\
\hline \multirow[t]{2}{*}{ Family history of other malignancies } & No & 39 & $76.5 \%$ \\
\hline & Yes & 12 & $23.5 \%$ \\
\hline
\end{tabular}


Laryngectomy was performed eventually to 46 patients out of 51 patients. 5 patients didn't undergo the surgery: two had complicated uncontrolled co-morbidities forbidding the general anesthetic measures and three refused to perform the surgery and preferred conservative medical management as chemotherapy and radiotherapy in private clinics.

The results of histological examination of the excised laryngeal tissue and draining lymph nodes were compared to the results obtained by $\mathrm{CT}$ and $\mathrm{U} / \mathrm{S}$ examination performed prior to surgery.

It was obvious that the lesions were mainly glottic in position seen in $71.7 \%$ (33/46) versus $36.9 \%$ (17/46) supraglottic and $8.6 \%(4 / 46)$ subglottic.

\begin{tabular}{|l|l|l|}
\hline Tumor location & No. & $\%$ \\
\hline glottic & 33 & 71.7 \\
\hline supraglottic & 17 & $36.9 \%$ \\
\hline subglottic & 4 & $8.6 \%$ \\
\hline
\end{tabular}

Detection results of invasion of intra and extra-laryngeal structures by $\mathrm{CT}$ and U/S were compared as follow:

\begin{tabular}{|c|c|c|c|c|c|c|c|c|c|}
\hline & TP & FP & $\mathrm{TN}$ & $\mathrm{FN}$ & Sensitivity & Specificity & PPV & NPV & Accuracy \\
\hline \multicolumn{10}{|c|}{ Glottic lesions } \\
\hline $\mathrm{CT}$ & 17 & 1 & 28 & 0 & $100.0 \%$ & $96.6 \%$ & $94.4 \%$ & $100.0 \%$ & $97.83 \%$ \\
\hline US & 13 & 2 & 27 & 4 & $76.5 \%$ & $93.1 \%$ & $86.7 \%$ & $87.1 \%$ & $86.95 \%$ \\
\hline \multicolumn{10}{|c|}{ Supraglottic lesions } \\
\hline $\mathrm{CT}$ & 17 & 1 & 28 & 0 & $100.0 \%$ & $93.4 \%$ & $96.6 \%$ & $0.0 \%$ & $97.83 \%$ \\
\hline US & 13 & 2 & 27 & 4 & $76.5 \%$ & $93.1 \%$ & $86.7 \%$ & $87.1 \%$ & $86.95 \%$ \\
\hline \multicolumn{10}{|c|}{ Subglottic lesions } \\
\hline $\mathrm{CT}$ & 4 & 1 & 41 & 0 & $100.0 \%$ & $97.6 \%$ & $80.0 \%$ & $100.0 \%$ & $97.83 \%$ \\
\hline US & 3 & 5 & 37 & 1 & $75.0 \%$ & $88.1 \%$ & $37.5 \%$ & $97.4 \%$ & $86.96 \%$ \\
\hline \multicolumn{10}{|c|}{ Anterior commissural infiltration } \\
\hline $\mathrm{CT}$ & 25 & 0 & 20 & 1 & $96.2 \%$ & $100.0 \%$ & $100.0 \%$ & $95.24 \%$ & $97.83 \%$ \\
\hline US & 23 & 2 & 18 & 3 & $88.5 \%$ & $90.0 \%$ & $92.0 \%$ & $85.71 \%$ & $89.13 \%$ \\
\hline \multicolumn{10}{|c|}{ Paraglottic fat infiltration } \\
\hline $\mathrm{CT}$ & 29 & 1 & 14 & 2 & $93.5 \%$ & $93.3 \%$ & $96.7 \%$ & $87.5 \%$ & $93.48 \%$ \\
\hline US & 28 & 2 & 13 & 3 & $90.3 \%$ & $86.7 \%$ & $93.33 \%$ & $81.25 \%$ & $89.13 \%$ \\
\hline \multicolumn{10}{|c|}{ Thyroid cartilage invasion } \\
\hline $\mathrm{CT}$ & 16 & 1 & 27 & 2 & $88.9 \%$ & $96.4 \%$ & $94.12 \%$ & $93.1 \%$ & $93.48 \%$ \\
\hline US & 16 & 3 & 25 & 2 & $88.9 \%$ & $89.3 \%$ & $84.21 \%$ & $92.59 \%$ & $89.13 \%$ \\
\hline \multicolumn{10}{|c|}{ Transglottic infiltration } \\
\hline $\mathrm{CT}$ & 9 & 1 & 36 & 0 & $100.0 \%$ & $97.3 \%$ & $90.0 \%$ & $100.0 \%$ & $97.83 \%$ \\
\hline US & 7 & 5 & 32 & 2 & $77.8 \%$ & $86.5 \%$ & $58.33 \%$ & $94.12 \%$ & $84.78 \%$ \\
\hline \multicolumn{10}{|c|}{ Extralaryngeal infiltration } \\
\hline $\mathrm{CT}$ & 9 & 1 & 36 & 0 & $100.0 \%$ & $97.3 \%$ & $90.0 \%$ & $100.0 \%$ & $97.83 \%$ \\
\hline US & 7 & 5 & 32 & 2 & $77.8 \%$ & $86.5 \%$ & $58.33 \%$ & $94.12 \%$ & $84.78 \%$ \\
\hline \multicolumn{10}{|c|}{ Regional lymph nodes assessment } \\
\hline $\mathrm{CT}$ & 11 & 3 & 28 & 4 & $73.3 \%$ & $90.3 \%$ & $78.57 \%$ & $87.5 \%$ & $84.78 \%$ \\
\hline US & 14 & 2 & 29 & 1 & $93.3 \%$ & $93.5 \%$ & $87.5 \%$ & $96.7 \%$ & $93.48 \%$ \\
\hline \multicolumn{10}{|c|}{ Recurrent laryngeal nerve invasion } \\
\hline CT & 13 & 1 & 31 & 1 & $92.9 \%$ & $96.9 \%$ & $92.86 \%$ & $96.9 \%$ & $95.65 \%$ \\
\hline US & 10 & 5 & 27 & 4 & $71.4 \%$ & $84.4 \%$ & $66.7 \%$ & $87.1 \%$ & $80.44 \%$ \\
\hline
\end{tabular}

None of the lesions showed vascularity on Doppler imaging

Free vocal cords mobility with phonation at the same side of the lesion was seen in the dynamic $\mathrm{U} / \mathrm{S}$ examination only in (30/46) $65.2 \%$ of the patients. 


\section{DISCUSSION:}

In our study, ultrasonography is proved to be a valuable supplementary method to CT and laryngoscopy in the assessment of laryngeal carcinoma even in male adults with some calcifications of the thyroid cartilage. Nevertheless, attempts have been made to use it in this area, largely to take advantage of its non invasive and real time imaging features.

It can be used as a screening tool ${ }^{7}$.

In this study, we provide evidence that ultrasonography could supply valuable information on the diagnosis of laryngeal carcinoma. It was found that ultrasonography was able to detect most of the laryngeal tumors. Once the tumor was detectable with ultrasonography, its primary site could be correctly localized. Furthermore, both the sensitivity and specificity were high in the evaluation of invasion to intra- and extralaryngeal structures.

The uncalcified areas of the larynx usually exist in the superior and middle parts of the bilateral lamina and enable effective ultrasound penetration. Some other anatomical sites are also suitable for the transmission of the ultrasound beam, e.g. the thyrohyoid and cricothyroid membranes. By choosing these acoustic windows, most of the tumors were detected in our study, in which male patients accounted for $92.1 \%$ $(47 / 51)$ in total. In addition, the laryngeal and hypopharyngeal regions could be visualized much better.

When the landmarks, i.e. ventricular bands and vocal cords, were clearly shown for localization, the glottic laryngeal tumor could be correctly located by ultrasonography with a rate [30 (90.9\%)/33], which was close to $\mathrm{CT}$ detection rate [31 $(93.9 \%) / 33](p=0.001)$.
In another study of 30 glottic carcinomas, a high ultrasonography detection rate $(96.7 \%)$ was shown, probably relating to fewer $\mathrm{T} 1$ cancers $(\mathrm{n}=5)$ in subjects. These results suggest that ultrasonography has a satisfying detection rate for laryngeal cancer mainly the glottis lesions even in male adults with thyroid cartilage calcification, excepting some of the early glottic carcinoma ${ }^{7}$.

Supraglottic carcinoma had a remarkably lower detection rate by ultrasonography of about [13 (76.4\%)/17) compared to [17 $(100 \%) / 17]$ by CT, yet least detection rate was seen in subglottic cancers with $\left[\begin{array}{ll}3 & (75 \%) / 4\end{array}\right]$ by ultrasonography compared to $[4(100 \%) / 4)$ by CT. This is mostly attributed to masking effect of air seen in rima vestibuli and infraglottisand the refractive shadowing as well as the accompanying orthopnea and patient's intolerance to supine position shortening the examination time which represented the main complaint in supra and infraglottic lesions.

A previous research of 14 advanced laryngeal carcinomas at a stage of $\mathrm{T} 2$ or above also showed a high accuracy [11 $(100.0 \%) / 11]$ in localizing the primary site of ultrasonography-visible lesions ${ }^{5}$.

However, some lesions were still not located correctly because of thyroid cartilage calcification or large tumor volumes. One primary glottic tumor with subglottic invasion was mistaken as a subglottic lesion on ultrasonography images because part of the lesion in the glottis was not delineated clearly with the calcification of thyroid cartilage. The remaining three cases with advanced stages (T4, $n=2$ and T3, $n=1)$ were not localized correctly because the bulky mass itself (transverse diameters, $3-4 \mathrm{~cm}$ and postero-anterior dimensions, $1.9-3.7 \mathrm{~cm}$ ) made it difficult to confirm the location of the primary site and two of them were not localized correctly by CT, either ${ }^{5}$. 
The evaluation of involvement of the related structures is critical because it supplies direct proof for tumour staging and determines the therapy plan $^{8}$

The lower specificity of U/S and CT in the detection of neoplastic spread to the paraglottic space of was related to the overestimation of tumor spread attributed to the peritumoral inflammatory reaction mostly due to biopsy taking or surrounding mild inflammatory process. (Zbären et al, 1997) ${ }^{9}$

We evaluated the mobility of the larynx by having the patients talk softly or relax after breath-holding. Asymmetrical movement or impaired mobility of the vocal cords and on real-time ultrasonography images was almost always associated with thyroid cartilage invasion with or without recurrent laryngeal nerve invasion upgrading the tumor to stage T4 with a sensitivity of $88.9 \%$ and a specificity of $89.3 \%$.

There are some limitations to the present study, some larynx subsites were not clearly evaluated by ultrasonography, such as aryepiglottic folds and posterior commissure. Another limitation was that only one examiner scanned the larynx, leading to the impossibility of determination in reproducibility and inter-observer reliability; however, this might be acceptable anyway, considering that it is not difficult for an examiner to perform ultrasonography examination of the laryngeal area after training.

In summary, most of the laryngeal tumors could be detected by sonography, even in male adults with some calcifications of the thyroid cartilage. Once the tumor is detected by ultrasonography, the localization of the primary focus and the assessment of tumor extension inside and outside the larynx are feasible, the results of which could be comparable to those of CT. Noticeably, comparable sensitivity between ultrasonography and CT was mainly noticed as regard the detection of thyroid cartilage invasion $(88.9 \%$ each), paraglottic fat infiltration (90.3\% and $93.5 \%$ ) and anterior commissure infiltration (88.5\% and $96.2 \%)$ respectively, also a real-time feature of ultrasonography could be used to view the mobility of the vocal cords.

\section{Conclusion:}

Ultrasonography could be used as a valuable supplementary imaging method to $\mathrm{CT}$ and laryngoscopy in the assessment of laryngeal carcinoma, even in male adults with some calcifications of the thyroid cartilage.

\section{REFERENCES:}

1. Tibbett $\mathrm{K}$ and Tan M: "Role of Advanced Laryngeal Imaging in Glottic cancer: Early Detection and Evaluation of Glottic Neoplasms" US National Library of Medicine, National Institute of Health, Otolaryngology Clinic North America, 2015, August;48:565-584.

2. Joshi MV, Vineet $\mathrm{W}$, and Suresh KM: "Imaging in laryngeal cancers" The Indian Journal of Radiology and Imaging, 2012, July-September ;22:209-226.

3. Xia CX, Zhu Q, Zhao HX, Yan F, Li SL, Zhang SM: "Usefulness of ultrasonography in the assessment of laryngeal carcinoma" British journal of Radiology, October, 2013; 86:10-30.

4. Arens $\mathrm{C}$ and Kraft M. "Endoscopic ultrasound of the larynx" US National Library of Medicine, National Institute of Health, Otolaryngology Clinic, North America, 2016, April; 24: 128-134.

5. Loveday EJ, Bleach NR, Van Hasselt CA, Metreweli C: "Ultrasound imaging in laryngeal cancer: a preliminary study." Clinical Radiology, 1994;49:676-682.

6. Chevallier P, Marcy PY, Arens C, Raffaelli C, Padovani B: "Applications of sonography in head and neck pathology" Larynx and hypopharynx, 2nd edition, 2002;456:165-191. 
7. Hu Q, Luo F, Zhu SY, Zhang Z, Mao YP, Hui Guan $X$ : "Staging of laryngeal carcinoma: comparison of high-frequency sonography and contrast-enhanced computed tomography". Clinical Radiology Journal, 2011, Septmber;67:140-170.

8. Lefebvre $\mathrm{J}$ and Ang K: "Larynx Preservation Consensus Panel Larynx preservation clinical trial design: key issues and recommendations-a consensus panel summary" International Journal Radiation Oncology Biology Physiology, 2009, August; 73:293-303.

9. Zbären $P$, Becker M, Läng H: "Staging of laryngeal cancer: endoscopy, computed tomography and magnetic resonance versus histopathology". European Archive Otorhinolaryngol 1997;254:117-122. 


\section{الملخص العربي}

المقدمة: طالما لم تستخدم الموجات الصوتية فى تشخيص اور ام الحنجرة بالثكل الأمثل بسبب وجود صعوبات

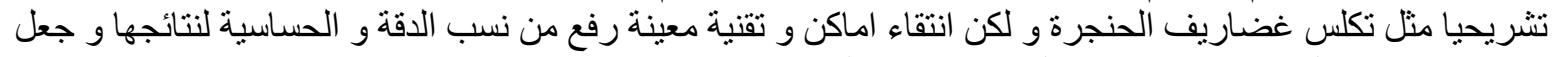

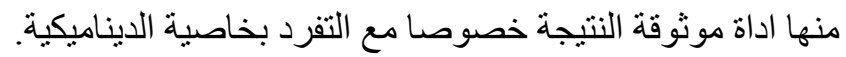

الهدف من البحث: هو در اسة امكانيات استخدام الموجات الصوتية لتشخيص و تخطيط أور ام الحنجرة الخبيثة بالمقارنة بالأشعة المقطعية.

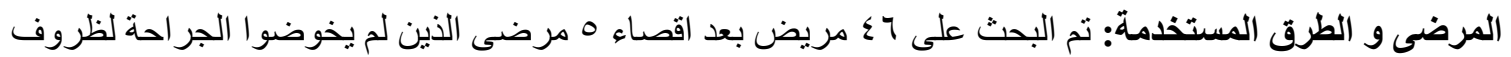

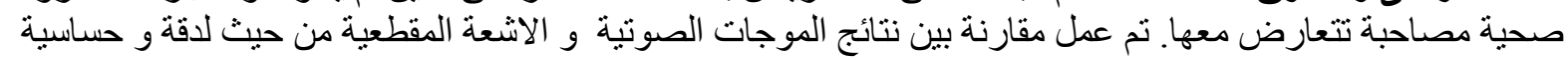

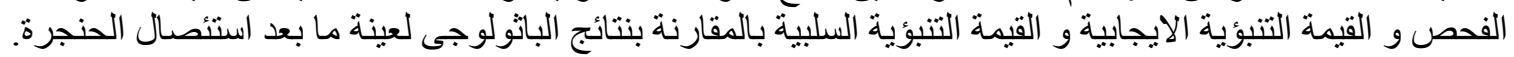

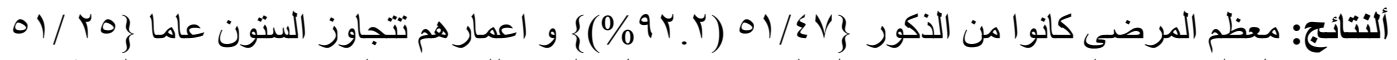

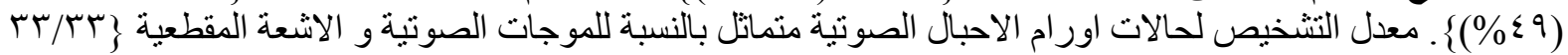

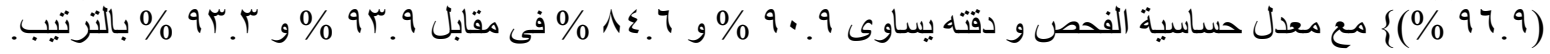

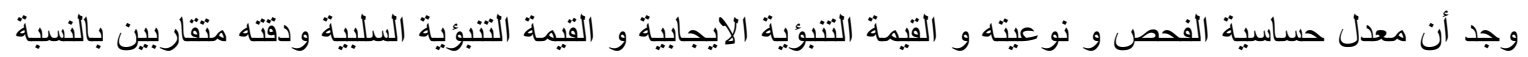

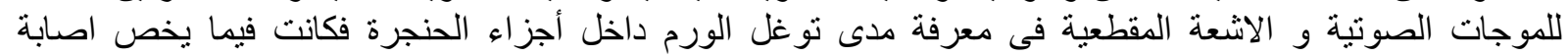

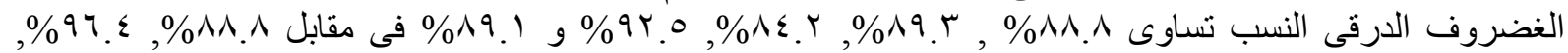

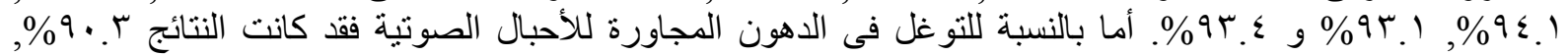

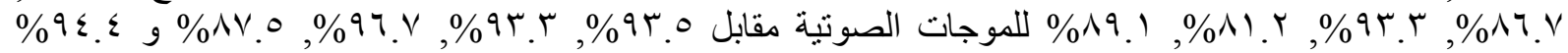

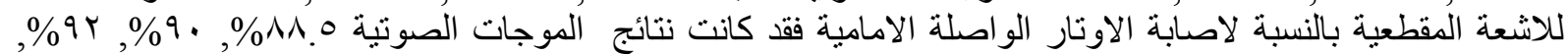

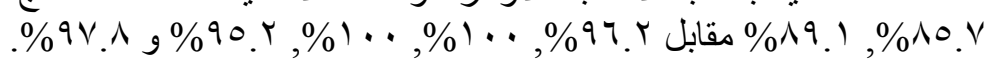
الخلاصة: نمثل الموجات الصوتية أداة تشخيص مكملة للأشعة المقطعية و منظار الحنجرة فى حالات. 